\title{
Potential soil moisture products from the aquarius radiometer and scatterometer using an observing system simulation experiment
}

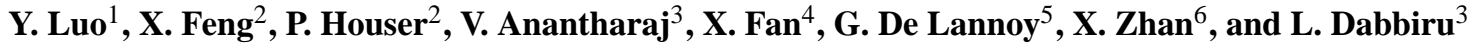 \\ ${ }^{1}$ I. M. Systems Group, Inc. at NOAA/NCEP/EMC, Camp Springs, MD 20746, USA \\ ${ }^{2}$ Department of Geography and Geoinformation Science, George Mason University, Fairfax, VA 22030, USA \\ ${ }^{3}$ Geosystems Research Institute, Mississippi State University, MS 39762, USA \\ ${ }^{4}$ Department of Geography and Geology, Western Kentucky University, Bowling Green, KY 42101, USA \\ ${ }^{5}$ Laboratory of Hydrology and Water Management, Ghent University, Ghent, Belgium \\ ${ }^{6}$ NOAA/NESDIS Center for Satellite Applications and Research, Camp Springs, MD 20746, USA
}

Correspondence to: X. Feng (xfeng@gmu.edu)

Received: 21 June 2012 - Published in Geosci. Instrum. Method. Data Syst. Discuss.: 13 July 2012

Revised: 1 February 2013 - Accepted: 1 February 2013 - Published: 20 February 2013

\begin{abstract}
Using an observing system simulation experiment (OSSE), we investigate the potential soil moisture retrieval capability of the National Aeronautics and Space Administration (NASA) Aquarius radiometer (L-band $1.413 \mathrm{GHz}$ ) and scatterometer (L-band, $1.260 \mathrm{GHz}$ ). We estimate potential errors in soil moisture retrievals and identify the sources that could cause those errors. The OSSE system includes (i) a land surface model in the NASA Land Information System, (ii) a radiative transfer and backscatter model, (iii) a realistic orbital sampling model, and (iv) an inverse soil moisture retrieval model.

We execute the OSSE over a $1000 \times 2200 \mathrm{~km}^{2}$ region in the central United States, including the Red and Arkansas river basins. Spatial distributions of soil moisture retrieved from the radiometer and scatterometer are close to the synthetic truth. High root mean square errors (RMSEs) of radiometer retrievals are found over the heavily vegetated regions, while large RMSEs of scatterometer retrievals are scattered over the entire domain. The temporal variations of soil moisture are realistically captured over a sparely vegetated region with correlations 0.98 and 0.63 , and RMSEs $1.28 \%$ and $8.23 \% \mathrm{vol} / \mathrm{vol}$ for radiometer and scatterometer, respectively. Over the densely vegetated region, soil moisture exhibits larger temporal variation than the truth, leading to correlation 0.70 and 0.67 , respectively, and RMSEs $9.49 \%$ and $6.09 \% \mathrm{vol} / \mathrm{vol}$ respectively. The domainaveraged correlations and RMSEs suggest that radiometer is more accurate than scatterometer in retrieving soil moisture.
\end{abstract}

The analysis also demonstrates that the accuracy of the retrieved soil moisture is affected by vegetation coverage and spatial aggregation.

\section{Introduction}

Soil moisture is a key land surface state variable and plays a crucial role in the variability of water and energy cycles (Koster et al., 2004). By controlling the partitioning of solar radiation into sensible and latent heat flux, as well as the partitioning of precipitation into evapotranspiration, infiltration and runoff, soil moisture regulates energy and water exchange between land surface and atmosphere and hence significantly influences the regional and global climate. Due to its recognized importance, routine soil moisture observations are critical for weather and climate prediction, drought and flood monitoring, water resource management and agricultural practice. The traditional in situ soil moisture measurements are sparsely distributed and only representative of local areas (Robock et al., 2000), thereby inadequately sampling the heterogeneous land surface. As an alternative, spaceborne microwave sensors have proven to be an effective way to monitor soil moisture at global scales (Owe et al., 1999; Kerr et al., 2010; Entekhabi et al., 2004).

To ensure success of a satellite observing system, it is indispensable to investigate the capability of new sensor designs to ensure a cost-effective selection of instruments and 
instrument configurations, and to prepare ground-based systems for the use of new data types. Several studies have been dedicated to adopting observing system simulation experiments (OSSEs; Masutani et al. 2006) to evaluate the reliability of soil moisture retrievals from the Hydrosphere State (Hydros) mission (Crow et al., 2005; Zhan et al., 2006). This study aims to investigate soil moisture retrieval capabilities from the Aquarius satellite, which is a new NASA Earth System Science Pathfinder mission launched in June 2011. This study was intentionally done before Aquarius launch to predict the usefulness and benefits of Aquarius data. Specifically, we employed an OSSE technique to simulate Aquarius measurements and invert them back into soil moisture products. Then the errors of the retrieved soil moisture were evaluated, and the potential sources for causing those errors were further identified. This study includes two new features compared to the earlier Hydro OSSE: the NASA Land Information System (LIS) to generate estimates of land surface variables, and a realistic orbital and instrument sampling to reproduce the observing overpass pattern.

\section{Aquarius instrument and OSSE}

Aquarius is a combined passive/active L-band microwave instrument that is developed to map the ocean salinity from space at a nominal resolution of $100 \mathrm{~km}$ every 7 days in a Sun-synchronous orbit at $657 \mathrm{~km}$ altitude (Le Vine et al., 2007). The instrument consists of a set of three radiometers that measure passive microwave emission from the surface, and a scatterometer that makes backscatter measurements, operating at $1.4 \mathrm{GHz}$ and $1.26 \mathrm{GHz}$ respectively. Aquarius has a $2.5-\mathrm{m}$ offset parabolic reflector with three antenna beams, which correspond to incidence angles of $29^{\circ}, 38^{\circ}$, and $46^{\circ}$ with the respective footprint sizes of $76 \times 94 \mathrm{~km}$, $84 \times 120 \mathrm{~km}$, and $96 \times 156 \mathrm{~km}$. The radiometer has Th, Tv, $\mathrm{T}+45$, and $\mathrm{T}-45$ polarizations, and the scatterometer has $\mathrm{HH}$, $\mathrm{HV}, \mathrm{VV}$, and $\mathrm{VH}$ polarizations. The design requirements for Aquarius are that the radiometer and scatterometer be adequately stable within $0.13 \mathrm{~K}$ and $0.1 \mathrm{~dB}$, respectively over 7 days.

To examine the soil moisture retrieval potential from the Aquarius instrument, we employ an OSSE to generate a synthetic soil moisture product. An OSSE consists of four components: (i) a land surface model (LSM) from LIS to generate land surface estimates, referred to as the nature run; (ii) a forward microwave emission and backscatter model (MEBM) to simulate radiometric brightness temperature and radar backscatter; (iii) an orbit and sensor model (OSM) to sample the synthetic observations based on the orbital and instrument characteristics; and (iv) an inverse retrieval model (RM) to derive synthetic soil moisture.

\subsection{Land surface model (LSM)}

The NASA LIS is a land surface modeling software platform that characterizes land surface states and fluxes through the integration of ground-based and satellite observations into land surface models (Kumar et al., 2006). It also incorporates scalable, high performance computing and data management technologies to enable high-resolution land surface modeling. The Community Land Model (CLM; Dai et al. 2003) in LIS is used to estimate surface fluxes and states variables, including soil moisture, soil temperature, and vegetation canopy temperature. Near-surface meteorological data used to drive CLM are from the North American Land Data Assimilation System (NLDAS; Cosgrove et al. 2003), which provides hourly, $0.125^{\circ}$-resolution forcing fields. The main ancillary static parameter datasets include (i) $1 \mathrm{~km}$ land cover types produced at the University of Maryland derived from the Advanced Very High Resolution Radiometer (AVHRR; Hansen et al. 2000), (ii) soil texture at $1 \mathrm{~km}$ from the State Soil Geographic (STATSGO) database, (iii) $1 \mathrm{~km}$ United States Geological Survey (USGS) GTOPO30 elevation and (iv) leaf area index (LAI) and stem area index (SAI) at $1 \mathrm{~km}$ from AVHRR. The $1 \mathrm{~km}$ parameter datasets are spatially averaged to $0.125^{\circ}(\sim 12 \mathrm{~km})$ CLM model resolution.

\subsection{Microwave emission and backscatter mode (MEBM)}

Using the LSM output at $0.125^{\circ}$ resolution, the MEBM (Dubois et al., 1995) is used to compute the synthetic brightness temperature and backscatter, corresponding to the Aquarius frequencies, polarizations and incidence angles. It calculates brightness temperature from soil and vegetation based on a layered single-scattering soil-vegetation model. The MEBM needs inputs of dynamic state variables, such as surface soil moisture, soil temperature and vegetation temperature, and static parameters, for instance soil roughness, vegetation single backscattering and vegetative structure coefficient with corresponding values chosen from Crow et al. (2005). The vegetation water content is a seasonally varying climatology at $1 \mathrm{~km}$ produced by Rodell et al. (2005) from the Moderate Resolution Imaging Spectroradiometer (MODIS). The backscatter MEBM derives the total scattering cross section from three components attributable to soil, vegetation and their interaction, which are functions of soil moisture and vegetation characteristics.

\subsection{Orbit and sensor model (OSM)}

The synthetic Aquarius radiometer and scatterometer observations need to be resampled to a fixed geolocation consistent with the orbital sampling and antenna spatial resolution to facilitate sensor data processing. We aggregate the $0.125^{\circ}$-resolution brightness temperature and backscatter 


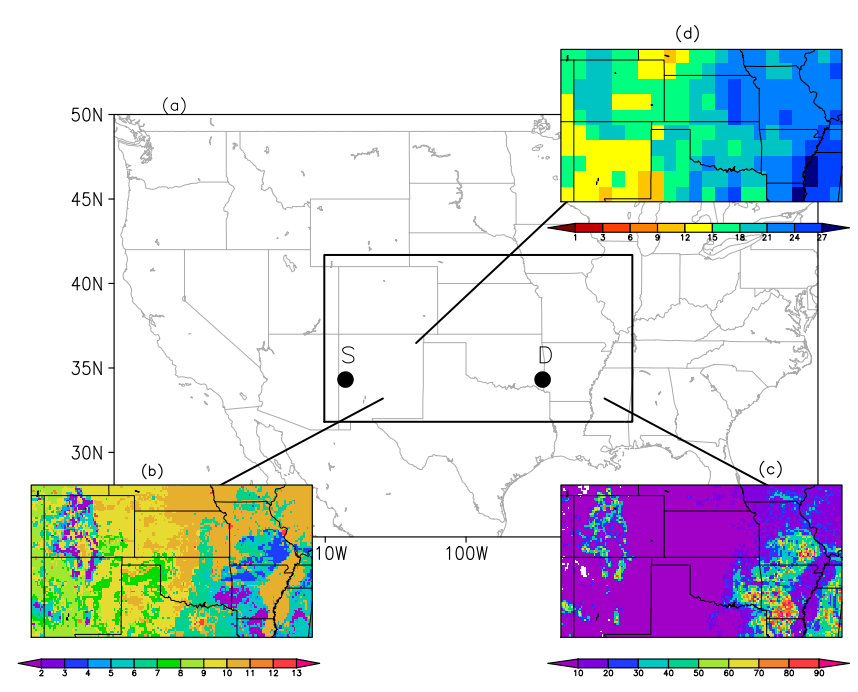

Fig. 1. (a) Simulation domain denoted by inner black box, (b) land cover category, (c) time-averaged vegetation water content $\left(\mathrm{kg} \mathrm{m}^{-2}\right)$ from October 2002 to September 2003 and (d) timeaveraged soil moisture (\% vol/vol) truth during September 2002 to September 2003. Black dots represent sparsely (S) and densely (D) vegetated pixels.

from MEBM to the Aquarius nominal resolution of $1^{\circ}$ at a 7-day revisit using orbital sampling software, Satellite Tool Kit (available at http://www.agi.com/resources/help/online/ stk/index.html). This approach precisely mimics the Aquarius sampling pattern and thereby yields more realistic microwave measurements than assuming twice-daily overpass in Crow et al. (2005).

\subsection{Retrieval model (RM)}

We invert the synthetic observations of brightness temperature and backscatter at $1^{\circ}$ resolution to soil moisture using the multi-polarization iterative algorithm developed by Njoku and Li (1999). In this inversion process, the roughness and vegetation parameters are assumed to be the same for all polarizations. A single soil moisture value is obtained from multi-polarized microwave measurements. The RM uses the same sets of mathematical equations as the MEBM; however, the RM simplifies the real emission/backscatter processes by assuming that the noises added to MEBM simulations are parts of the actual processes. The real noises are not known in the retrieval process. The soil and vegetation parameters are the same as those used for MEBM but are linearly aggregated to $1^{\circ}$ resolution. The surface topography is assumed to be flat over the $1^{\circ}$ domain.

\section{Simulation domain and design}

The Aquarius OSSE is carried out over the central United States $\quad\left(31.8125^{\circ}-41.6875^{\circ} \mathrm{N}, \quad 110.0625^{\circ}-88.1875^{\circ} \mathrm{W}\right.$; Fig. 1a), encompassing the Red-Arkansas river basin. Over this region, soil moisture has been shown to exert a dominant influence on water and energy variability (Koster et al., 2004). The selected study area has limited vegetation and inland water coverage (Fig. 1b), a favorable location for more accurate soil moisture retrievals. Meanwhile, the study area has a pronounced west-east contrast with vegetation decreasing towards the west (Fig. 1c). The CLM has spatial resolution of $0.125^{\circ}$ and time step of $30 \mathrm{~min}$. After a spinup from March 2000 to September 2002, CLM is run 13 months spanning from September 2002 to September 2003, which captures the seasonal variations of diverse land surface conditions. The nature run soil moisture is extracted from a $5 \mathrm{~cm}$ surface CLM layer, corresponding to the sensing depth of the Aquarius L-band radiometer and scatterometer (Entekhabi et al., 2004). The reference "truth" is defined as the soil moisture at $1^{\circ}$ resolution Aquarius footprint (Fig. 1d) via direct aggregation of the original $0.125^{\circ}$ nature run. The Aquarius satellite will have overpass times of 06:00 and 18:00 local time. Since the surface temperature gradient is more stable and uniform at 06:00 than at 18:00 (Hornbuckle and England, 2005), we only choose the results at 06:00 (13:00 UTC) to address OSSE retrievals in this analysis.

The retrieved Aquarius soil moisture is subject to measurement error due to instrument noise and calibration error, and retrieval uncertainty arising from resolution degradation of soil and vegetation parameters. To account for uncertainty of measurement and retrieval process, we intend to be consistent with Zhan et al. (2006) by adding spatially and temporally uncorrelated Gaussian noise with standard deviations of $1 \mathrm{~K}$ and $0.5 \mathrm{~dB}$, for brightness temperature and backscatter, $20 \%, 5 \%$ and $20 \%$ for surface roughness, vegetative structure coefficient and vegetation water content, as well as $1.5 \mathrm{~K}$ for both soil and vegetation temperature to the $1^{\circ}$ pixels.

\section{Results analysis}

\subsection{Soil moisture retrieval}

Using the OSSE design, the retrieved soil moisture from synthetic brightness temperature and backscatter for the simulation domain at the $1^{\circ}$ resolution during 1 to 7 September in 2002 is shown in Fig. 2. For both radiometer- and scatterometer-based soil moisture with a specified incidence angle, the simulated soil moisture sampling pattern varies substantially within a 7-day cycle. The spatial coverage gradually increases with the ascending incidence angles of $29^{\circ}$, $38^{\circ}$, and $46^{\circ}$ corresponding to the increasing footprint sizes of the three Aquarius instrument beams. We average soil moisture estimates from three incidence angles over 7 days 

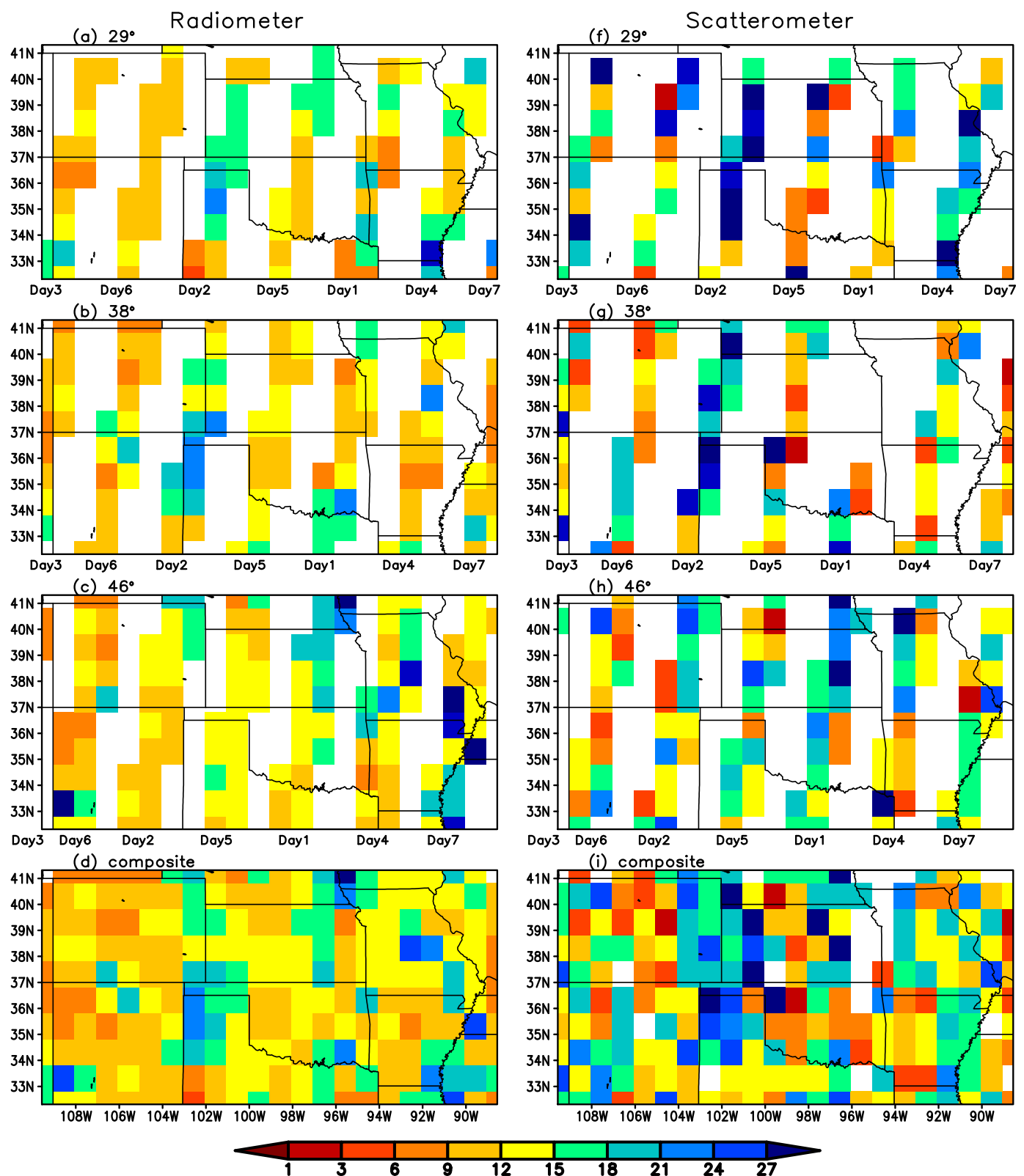

Fig. 2. The retrieved soil moisture (\% vol/vol) at incidence angles of (a) and (f) $29^{\circ}$, (b) and (g) $38^{\circ}$, and (c) and (h) $46^{\circ}$ for synthetic observations of radiometer and scatterometer, and their respective 7-day averaged composite (d) and (i) over the simulation domain during 1 to 7 September 2002 .

and derive the composite spatial map for the radiometer and scatterometer as shown in Fig. $2 \mathrm{~d}$ and i. The radiometer measurements almost cover the entire simulation domain, whereas the scatterometer shows several missing values. Dry conditions mostly dominate the simulation domain with wet areas scattered over northern Texas, eastern Kansas, and southern Arkansas.

To further examine the ability of the Aquarius OSSE in describing the soil moisture temporal variability, we choose two representative grid cells with comparably large vegetation contrast, sparsely and densely vegetated pixels, as defined in Fig. 1a, corresponding to the latitudes and longitudes of $34.3125^{\circ} \mathrm{N}, 108.562^{\circ} \mathrm{W}$ and $34.3125^{\circ} \mathrm{N}, 94.5625^{\circ} \mathrm{W}$. The time variations of daily soil moisture retrievals from the radiometer and scatterometer at $29^{\circ}$ are shown in Fig. 3 at these two chosen pixels compared with the truth. For the sparsely vegetated pixel, both the radiometer- and scatterometerretrieved soil moisture consistently reveal that soil is wet in early winter and spring, and dry in summer, which is in agreement with the dry and wet episodes shown in the 

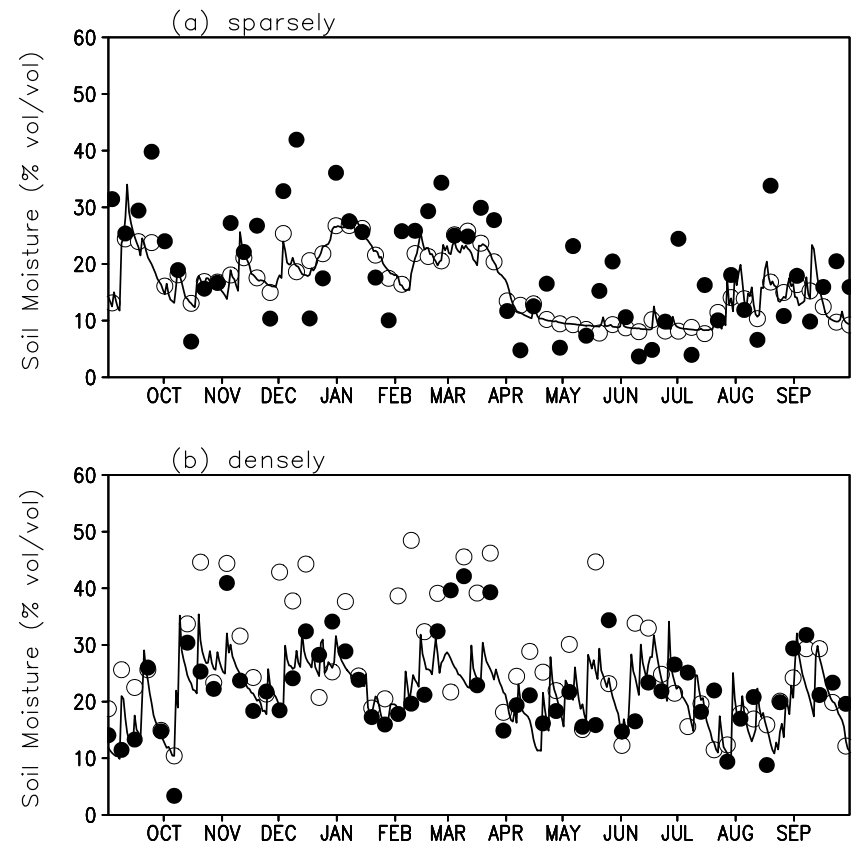

Fig. 3. Time variations of daily soil moisture (\% vol/vol) retrievals from radiometer (open circle) and scatterometer (closed circle) at $29^{\circ}$ incidence angle compared with the truth (black line) at (a) sparsely and (b) densely vegetated pixels from September 2002 to September 2003.

truth. The correlation coefficients between retrievals and the truth are 0.98 and 0.63 , statistically significant at the $5 \%$ level. The root mean square errors (RMSEs) are $1.28 \%$ and $8.23 \% \mathrm{vol} / \mathrm{vol}$, respectively. In comparison with the sparsely vegetated pixel, soil moisture retrievals at densely vegetated pixels tend to display larger temporal variation. In particular, the simulated amplitude of variation is overestimated and the temporal phase is not well captured by the radiometer retrieval, leading to correlation coefficients of 0.70 and 0.67 , and RMSEs of $9.49 \%$ and $6.09 \% \mathrm{vol} / \mathrm{vol}$, respectively. Contrary to expectation, the retrieval accuracy of the scatterometer increases in the presence of vegetation, likely being caused by the error cancelling involved in the retrieval process. It is noticeable in Fig. $3 \mathrm{~b}$ that the radiometer has larger soil moisture estimate uncertainties from mid-October to April compared to warm months. The reason is that the densely vegetated pixel has higher vegetation water content during the cold season than in warm season, likely attributed to winter wheat. These results indicate that vegetation cover has more impact on radiometer soil moisture retrievals in winter months than in summer months.

\subsection{Error analysis}

To further identify the accuracy of the soil moisture, we calculate the RMSE between composite retrievals and the truth at $1^{\circ}$ from September 2002 to September 2003 (Fig. 4). Gen-

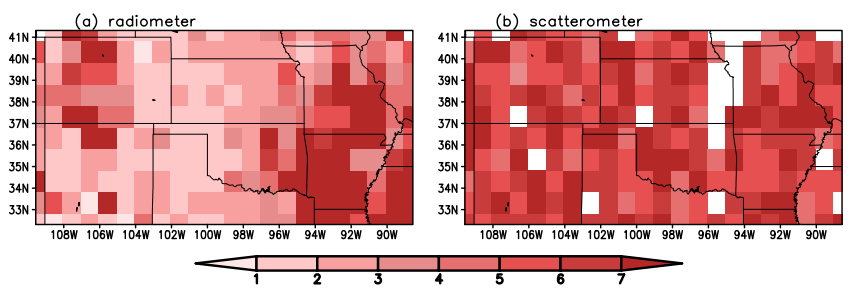

Fig. 4. The root mean square error (RMSE, \% vol/vol) between the truth and soil moisture retrieval composites for (a) radiometer (left) and (b) scatterometer (right) from September 2002 to September 2003 .

erally speaking, the radiometer-retrieved soil moisture has lower observed errors than the scatterometer soil moisture retrievals. High RMSEs of radiometer soil moisture retrievals are confined over the western end and eastern portion of the region with high vegetation water content, whereas the large values of RMSE of scatterometer-derived products are pretty irregular, scattered over the simulation domain.

In order to see the accuracy of different measurements, we calculate the correlations and RMSEs for radiometer and scatterometer soil moisture retrievals at each incidence angle (Table 1a). The calculations are derived by pooling retrievals from all of the $1^{\circ}$ pixels in the OSSE domain during the entire simulation period. Soil moisture retrievals from radiometer have a larger correlation and lower RMSE than those from scatterometer for each incidence angle. In addition, the highest accuracies for radiometer and scatterometer are at incidence angles of $29^{\circ}$ and $46^{\circ}$, respectively. If the soil moisture retrievals at three incidence angles are combined together, the resultant correlations and RMSEs of composites are 0.78 and 0.68 , as well as $5.94 \%$ and $6.64 \% \mathrm{vol} / \mathrm{vol}$ for radiometer and scatterometer.

Several potential factors are responsible for degrading the performance of the Aquarius soil moisture retrievals. Firstly, the microwave measurement errors are accounted for by adding Gaussian white noise for radiometer and scatterometer measurements. This is a gross simplification of the truth due to our limited knowledge about the actual noise level. Secondly, the substantial RMSEs over eastern part in Fig. 4 are attributed to the high vegetation water content, which is claimed to decrease the microwave measurement soil moisture sensitivity (Entekhabi et al., 1999). To circumvent this problem, we artificially exclude the grid cells with vegetation water content higher than $3 \mathrm{~kg} \mathrm{~m}^{-2}$. It is noted that soil moisture retrievals from radiometer improve accuracy (Table $1 \mathrm{~b}$ ) as they are more sensitive to vegetation water content as revealed in Zhan et al. (2006). Lastly, linearly aggregating microwave measurements and surface parameters from the $0.125^{\circ}$ resolution to the coarse Aquarius $1^{\circ}$ footprint also contribute to the footprint-scale retrieved soil moisture errors. Land surfaces across a $1^{\circ}$ footprint have very different responses that likely results in representativeness errors when averaged. However, deconvolving overlapping antenna gain 
Table 1. The correlation coefficient (corr) and root mean square error (RMSE, \%vol/vol) between the truth and soil moisture retrievals at incidence angles of $29^{\circ}, 38^{\circ}$ and $46^{\circ}$ from synthetic radiometer and scatterometer measurements, and their respective composite from September 2002 to September 2003 for (a) the entire domain and (b) the entire domain but the grid cells with vegetation water content higher than $3 \mathrm{~kg} \mathrm{~m}^{-2}$ screened out.

\begin{tabular}{|c|c|c|c|c|c|c|c|c|}
\hline \multicolumn{9}{|l|}{ (a) } \\
\hline \multirow{2}{*}{ Measurement } & \multicolumn{2}{|c|}{$29^{\circ}$} & \multicolumn{2}{|c|}{$38^{\circ}$} & \multicolumn{2}{|c|}{$46^{\circ}$} & \multicolumn{2}{|c|}{ Composite } \\
\hline & corr & RMSE & corr & RMSE & corr & RMSE & corr & RMSE \\
\hline Radiometer & 0.82 & 5.44 & 0.77 & 5.74 & 0.77 & 6.41 & 0.78 & 5.94 \\
\hline Scatterometer & 0.65 & 7.93 & 0.66 & 6.64 & 0.74 & 5.66 & 0.68 & 6.64 \\
\hline
\end{tabular}

(b)

\begin{tabular}{|c|c|c|c|c|c|c|c|c|}
\hline \multirow{2}{*}{ Measurement } & \multicolumn{2}{|c|}{$29^{\circ}$} & \multicolumn{2}{|c|}{$38^{\circ}$} & \multicolumn{2}{|c|}{$46^{\circ}$} & \multicolumn{2}{|c|}{ Composite } \\
\hline & corr & RMSE & corr & RMSE & corr & RMSE & corr & RMSE \\
\hline Radiometer & 0.90 & 3.31 & 0.82 & 4.24 & 0.82 & 4.65 & 0.84 & 4.18 \\
\hline Scatterometer & 0.63 & 7.94 & 0.65 & 6.73 & 0.76 & 5.51 & 0.69 & 6.62 \\
\hline
\end{tabular}

patterns or using information from the high-resolution land surface model or digital elevation model may provide information on the effect of spatial variability on the signal, or may allow the signal to be downscaled to a higher resolution. As Fig. 5 illustrates, the brightness temperature and backscatter nonlinearly vary with the soil moisture and vegetation water content. However, such nonlinear relationships cannot be reflected by linear aggregation used in the OSSE, which is confirmed by Zhan et al. (2008). These error sources would provide us valuable guidance for future designs in spaceborne sensor and retrieval algorithm to effectively improve soil moisture retrieval accuracy.

\section{Summary}

A potential Aquarius soil moisture retrieval product using an OSSE technique is presented over the Red-Arkansas river basin. The retrieved soil moisture errors are estimated, and the sources for causing those errors involved in measurement and retrieval process are also identified. This is the first soil moisture OSSE aimed specifically at Aquarius and one of the few studies focused on retrieving soil moisture from both active and passive microwave observations. The Aquarius OSSE system has several distinct features: (1) a current state-of-the-art LSM model encapsulated in LIS, which integrates surface and atmosphere observations; (2) a realistic OSM model, which mimics the Aquarius orbit and instrument sampling; (3) realistic ancillary data, such as the vegetation parameter taken from MODIS; and (4) a larger simulation domain and longer simulation period than used in the previous Hydros OSSE work. All of these improved design aspects make this study unique and advantageous to investigate and assess the capability of Aquarius measurements.
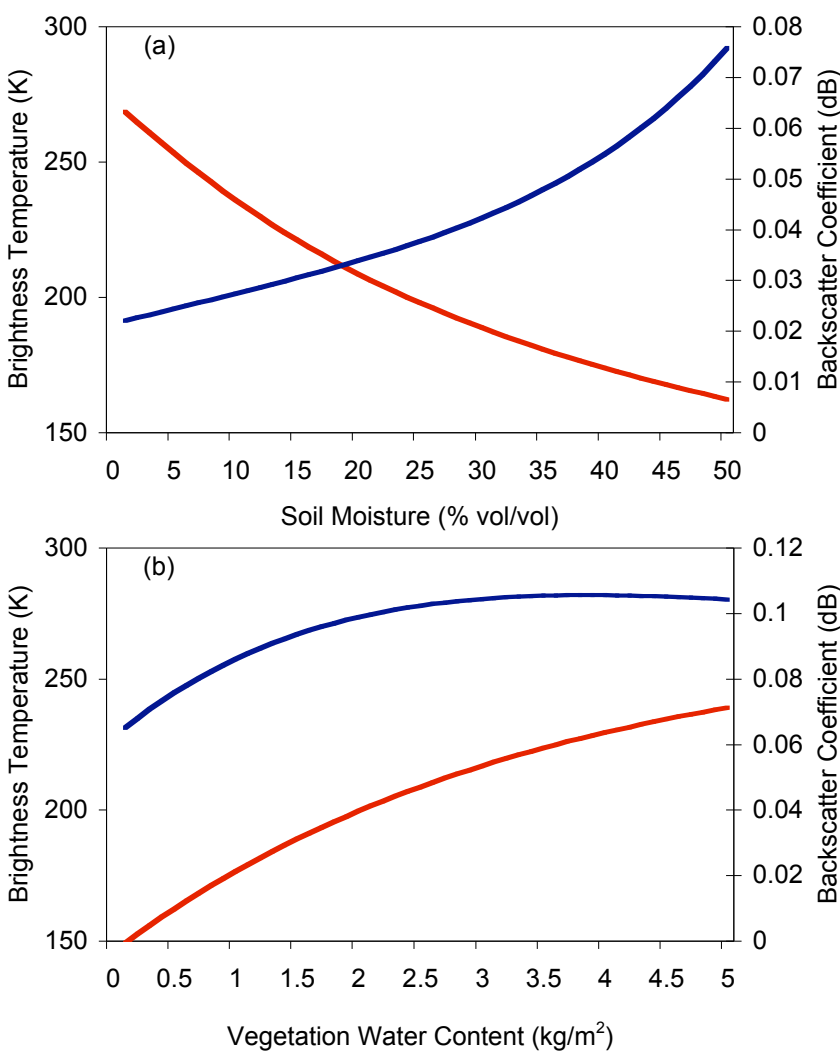

Fig. 5. The variations of synthetic observations of brightness temperature $(\mathrm{K}$, red line) and backscattering coefficient ( $\mathrm{dB}$, blue line) at $38^{\circ}$ incidence angle with $\mathrm{H}$ polarization in relation to (a) soil moisture $(\% \mathrm{vol} / \mathrm{vol})$ and (b) vegetation water content $\left(\mathrm{kg} \mathrm{m}^{-2}\right)$ over clay soil covered with evergreen needleleaf/broadleaf. Soil temperature and vegetation temperature are set to be $300 \mathrm{~K}$; vegetation water content is $0.5 \mathrm{~kg} \mathrm{~m}^{-2}$ in (a), and soil moisture is $3 \%$ $\mathrm{vol} / \mathrm{vol} \mathrm{in} \mathrm{(b).}$ 
Radiometer soil moisture retrievals generally have lower spatial RMSEs than scatterometer-derived soil moisture. High RMSEs of radiometer products are mainly found over the heavily vegetated region, while large values of RMSE of scatterometer products are dispersed over the simulation domain. The temporal variation of soil moisture from both radiometer and scatterometer retrieval is well represented over the sparsely vegetated pixel with statistically significant correlations of 0.98 and 0.63 , and RMSEs of $1.23 \%$ and $8.23 \%$ $\mathrm{vol} / \mathrm{vol}$. In contrast, over densely vegetated pixels, the simulated soil moisture displays larger temporal variation than the truth, resulting in lower correlations of 0.70 and 0.67 , and higher RMSEs of $9.49 \%$ and $6.09 \% \mathrm{vol} / \mathrm{vol}$. The correlations and RMSEs derived by pooling soil moisture retrievals from all $1^{\circ}$ pixels in the OSSE domain during the simulation period further suggest that radiometer measurements are more accurate than scatterometer measurements in retrieving soil moisture.

Uncertainties in soil moisture retrieval products come from a variety of potential sources, such as measurement error, vegetation and spatial aggregation. We seek to evaluate the impact of vegetation, land surface heterogeneity and inland water on the retrieved soil moisture via sensitivity studies for a few cases using a different LSM or assimilation strategy in a future study.

Acknowledgements. This work was supported by the NASA Rapid Prototyping Capability (RPC) experiment project. Gabriëlle De Lannoy is a postdoctoral research fellow of the Research Foundation Flanders (FWO). We would like to acknowledge the comments from two anonymous reviewers that improved the manuscript. We would also like to thank Wade Crow for providing the Hydros OSSE nature run as reference, and Sujay Kumar and James Geiger for assisting LIS implementation.

Edited by: H. Svedhem

\section{References}

Cosgrove, B. A., Lohmann, D., Mitchell, K., Houser, P. R., Wood, E. F., Schaake, J., Robock, A., Marshall, C., Sheffield, J., Luo, L., Duan, Q., Pinker, R., Tarpley, J. D., Higgins, R., and Meng, J.: Real-time and retrospective forcing in the North American Land Data Assimilation System (NLDAS) project, J. Geophys. Res., 108, 8842, doi:10.1029/2002JD003118, 2003.

Crow, W. T., Chan, T., Entekhabi, D., Houser, P. R., Hsu, A., Jackson, T. J., Njoku, E., O'Neill, P. E., Shi, J. C., and Zhan, X.: An observing system simulation experiment for hydros radiometeronly soil moisture products, IEEE Trans. Geosci. Remote Sens., 43, 1289-1303, 2005.

Dai, Y., Dickinson, R. E., Baker, I., Bonan, G., Bosilovich, M., Denning, S., Dirmeyer, P., Houser, P., Niu, G., Oleson, K., Schlosser, A., and Yang, Z.-L.: The Common Land Model (CLM), B. Am. Meteorol. Soc., 84, 1013-1023, 2003.
Dubois, P. C., Zyl, J. V., and Engman, E.: Measuring soil moisture with imaging radar, IEEE Trans. Geosci. Remote Sens., 33, 915926, 1995.

Entekhabi, D., Asrar, G. R., Betts, A. K., and Beven, K. J.: An agenda for land-surface hydrology research and a call for the second international hydrology decade, B. Am. Meteorol. Soc., 80, 2043-2058, 1999.

Entekhabi, D., Njoku, E., Houser, P., Spencer, M., Doiron, T., j. Smith, Girard, R., Belair, S., Crow, W., Jackson, T., and Kerr, Y.: The Hydrosphere State (HYDROS) mission concept: An earth system pathfinder for global mapping of soil moisture and land freeze/thaw, IEEE Trans. Geosci. Remote Sens., 42, 2184 2195, 2004.

Hansen, M., DeFries, R., Townshend, J., and Sohlberg, R.: Global land cover classification at $1 \mathrm{~km}$ spatial resolution using a classification tree approach, Int. J. Remote Sens., 21, 1331-1364, 2000.

Hornbuckle, B. K. and England, A.: Diurnal variation of vertical temperature gradients within a field of maize: Implications for Satellite microwave radiometry, IEEE Trans. Geosci. Remote Sens., 2, 74-77, 2005.

Kerr, Y. H., Waldteufel, P., Wigneron, J.-P., Delwart, S., Cabot, F., Boutin, J., Escorihuela, M.-J., Font, J., Reul, N., Gruhier, C., Juglea, S. E., Drinkwater, M. R., Hahne, A., Martín-Neira, M., and Mecklenburg, S.: The SMOS mission: New tool for monitoring key elements of the global water cycle, Proc. IEEE, 98, 666-687, 2010.

Koster, R. D., Dirmeyer, P. A., Guo, Z. C., Bonan, G., Chan, E., Cox, P., Gordon, C. T., Kane, S., Kowalczyk, E., D. Lawrence, Liu, P., and Lu, C.: Regions of strong coupling between soil moisture and prediction, Science, 305, 1138-1140, 2004.

Kumar, S., Peters-Lidard, C. D., Tian, Y., Houser, P. R., Geiger, J., Olden, S., Lighty, L., Eastman, J. L., Doty, B., Dirmeyer, P., Adams, J., Mitchell, K., wood, E. F., and Sheffield, J.: Land Information System - An interoperable framework for high resolution land surface modeling, Environ. Modell. Softw., 21, 14021615, 2006.

Le Vine, D. M., Lagerloef, G. S. E., Colomb, F. R., Yueh, S. H., and Pellerano, F. A.: An instrument to monitor sea surface salinity from space, IEEE Trans. Geosci. Remote Sens., 45, 2040-2050, 2007.

Masutani, M., Woollen, J. S., Lord, S. J., Kleespies, T. J., Emmitt, G. D., Sun, H., Wood, S. A., Greco, S., Terry, J., Treadon, R., and Campana, K. A.: Observing system simulation experiments at NCEP, NCEP Office Note No. 451, National Centers for Environmental Prediction, Camp Springs, Maryland, 2006.

Njoku, E. G. and Li, L.: Retrieval of land surface parameters using passive microwave measurements at 6 to $18 \mathrm{Ghz}$, IEEE Trans. Geosci. Remote Sens., 37, 79-93, 1999.

Owe, M., de Griend, A. A. V., de Jeu, R., de Vries, J. J., Seyhan, E., and Engman, E. T.: Estimating soil moisture from satellite microwave observations: Past and ongoing projects, and relevance to GCIP, J. Geophys. Res., 104, 19735-19742, 1999.

Robock, A., Vinnikov, K. Y., Srinivasan, G., Entin, J. K., Hollinger, S. E., Speranskaya, N. A., Liu, S. X., and Namkhai, A.: The global soil moisture data bank, B. Am. Meteorol. Soc., 81, 12811299, 2000.

Rodell, M., Chao, B. F., Au, A. Y., Kimball, J. S., and McDonald, K. C.: Global biomass variation and its geodynamic effects, Earth 
Interactions, 9, 1982-1998, 2005.

Zhan, X., Houser, P. R., Walker, J. P., and Crow, W. T.: A Method for retrieving high-Resolution Surface Soil Moisture from Hydros LBand Radiometer and Radar Observations, IEEE Trans. Geosci. Remote Sens., 41, 215-229, 2006.
Zhan, X., Crow, W. T., Jackson, T. J., and O'Neill, P.: Improving Space-borne Radiometer Soil Moisture Retrievals with Alternative Aggregation Rules for Ancillary Parameters, IEEE Trans. Geosci. Remote Sens., 5, 261-265, 2008. 